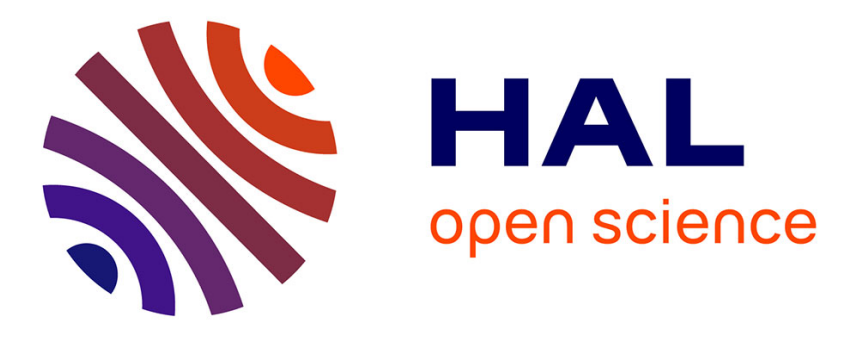

\title{
Shear behavior of thermoformed woven-textile thermoplastic prepregs: An analysis combining bias-extension test and X-ray microtomography
}

M. Gassoumi, S. Rolland Du Roscoat, P. Casari, P. Dumont, L. Orgeas, F. Jacquemin

\section{To cite this version:}

M. Gassoumi, S. Rolland Du Roscoat, P. Casari, P. Dumont, L. Orgeas, et al.. Shear behavior of thermoformed woven-textile thermoplastic prepregs: An analysis combining bias-extension test and X-ray microtomography. 20TH International ESAFORM Conference on Material Forming (esaform 2017), Apr 2017, Dublin, Ireland. 10.1063/1.5008011 . hal-01980318

\section{HAL Id: hal-01980318 https://hal.science/hal-01980318}

Submitted on 5 Mar 2019

HAL is a multi-disciplinary open access archive for the deposit and dissemination of scientific research documents, whether they are published or not. The documents may come from teaching and research institutions in France or abroad, or from public or private research centers.
L'archive ouverte pluridisciplinaire HAL, est destinée au dépôt et à la diffusion de documents scientifiques de niveau recherche, publiés ou non, émanant des établissements d'enseignement et de recherche français ou étrangers, des laboratoires publics ou privés. 


\title{
Shear behavior of thermoformed woven-textile thermoplastic prepregs: an analysis combining bias- extension test and $X$-ray microtomography
}

\author{
M. Gassoumi ${ }^{1,2,3,4, a}$, S. Rolland du Roscoat ${ }^{2, b}$, P. Casari ${ }^{3, c}$, P.J.J. Dumont ${ }^{4, d}$ \\ L. Orgéas ${ }^{2, e}$, F. Jacquemin ${ }^{3, f}$ \\ ${ }^{1}$ Institut de Recherche Technologique Jules Verne, Chemin du Chaffault, 44340, Bouguenais, France \\ ${ }^{2}$ Univ. Grenoble Alpes, CNRS, Grenoble INP, 3SR, F-38000 Grenoble, France \\ ${ }^{3}$ Institut de Recherche en Génie Civil et Mécanique, GeM, CNRS UMR 6183, 44600 Saint-Nazaire, France \\ ${ }^{4}$ Univ. Lyon, LaMCoS, INSA-Lyon, CNRS UMR5259, F-69621, Lyon, France \\ a) mohamed.gassoumi@irt-jules-verne.fr \\ b) sabine.rollandduroscoat@3sr-grenoble.fr \\ c) Pascal.Casari@univ-nantes.fr \\ d) pierre.dumont@insa-lyon.fr \\ e) Corresponding author: laurent.orgeas@3sr-grenoble.fr \\ f) frederic.jacquemin@univ-nantes.fr
}

\begin{abstract}
Thermoforming allows the manufacture of structural parts for the automotive and aeronautical domains using long fiber thermoplastic prepregs with short cycle times. During this operation, several sheets of molten prepregs are stacked and subjected to large macroscale strains, mainly via in-plane shear, out-of-plane consolidation or dilatation, and bending of the fibrous reinforcement. These deformation modes and the related meso and microstructure evolutions are still poorly understood. However, they can drastically alter the end-use macroscale properties of fabricated parts. To better understand these phenomena, bias extension tests were performed using specimens made of several stacked layers of glass woven fabrics and polyamide matrix. The macroscale shear behavior of these prepregs was investigated at various temperatures. A multiscale analysis of deformed samples was performed using X-ray microtomography images of the deformed specimens acquired at two different spatial resolutions. The low-resolution images were used to analyze the deformation mechanisms and the structural characteristics of prepregs at the macroscale and bundle scales. It was possible to analyze the 3D shapes of deformed samples and, in particular, the spatial variations of their thickness so as to quantify the out-of-plane dilatancy or consolidation phenomena induced by the in-plane shear of prepregs. At a lower scale, the analysis of the high-resolution images showed that these mechanisms were accompanied by the growth of pores and the deformation of fiber bundles. The orientation of the fiber bundles and its through-thickness evolution were measured along the weft and warp directions in the deformed samples, allowing the relevance of geometrical models currently used to analyze bias extension tests to be discussed. Results can be used to enhance the current rheological models for the prediction of thermoforming of thermoplastic prepregs.
\end{abstract}

\section{INTRODUCTION}

Thermoplastic polymers reinforced by woven fabrics become attractive materials for automotive and aeronautic structural applications because of their good thermal stability, high toughness and damage tolerance. Their properties highly depend on their meso and microstructures that are drastically affected during thermoforming. Thermoforming consists of four stages. First, the pre-consolidated thermoplastic blank is preheated so that the matrix reaches its molten state. Then, the prepreg is automatically transported to a stamping/compression press, where it is stamped and then compressed in a mold. Finally, the mold is maintained closed under pressure at low temperature in order to cool down the composite, enhance its consolidation and avoid the formation of porosity. In case of woven thermoplastic prepregs, five main deformation mechanisms occur $(1,2)$ : in-plane shear and extension, out-of-plane shear, compression and bending.

In-plane-shear is the predominant deformation mode (3) and is associated by the in-plane rotation of the yarns. The bias-extension test has been recognized as a proper mechanical loading to characterize this deformation mode (4-6). It is an off-axis tensile test where warp and weft directions are initially at $\pm 45^{\circ}$ with respect to the tensile direction. When the initial gauge length of the sample $L_{0}$ is larger than twice the sample width $l_{0}$, several zones with three 
different deformation modes appear: a uniform sheared zone in the center of the gauge length, four half-sheared zones and a non-deformed zone. Assuming that (i) fibers are inextensible, (ii) no slip occurs in the sample and (iii) that three different zones exist in terms of shear deformation, an analytical estimate of the global in-plane shear angle $\gamma$ as a function of fabric size and the current displacement $\delta$ can be obtained from geometrical considerations (7):

$$
\gamma=\frac{\pi}{2}-2 \cdot \cos ^{-1}\left(\frac{D+\delta}{\sqrt{2} \mathrm{D}}\right)
$$

Where $D=L_{0}-l_{0}$. However, other experimental studies (5) have shown that the true shear angle could differ from that predicted by Eq.1, with discrepancies that could exceed $5^{\circ}$. In addition, the existence of well-defined halfsheared zones can be questionable. At last, the out-of-plane deformation induced during the bias-extension test is rarely analyzed, as most of experiments consist of 2D observations of macroscopic and surface deformation mechanisms. Thus, using current experimental results, it is still not possible to propose fine constitutive equations for the mechanical behavior of thermoplastic prepregs during thermoforming that account for the complex interplay between the thermomechanical history, the matrix rheological properties the fabric architecture and the corresponding 3D deformation mechanisms at the microscopic (intra-bundle scale), mesoscopic (fiber bundle scale) and macroscopic (specimen scale) scales. For that purpose, bias-extension tests were performed on woven glass fiber (GF) fabrics impregnated with PA66 at several different temperatures. The mechanical results show the thermal dependence of the mechanical response of these thermoplastic prepregs. In addition, the evolution of several local structural descriptors (shear angle, fiber content and thickness variations) were investigated using 3D X-ray microtomography images of the deformed specimens to better characterized flow-induced mesostructrures.

\section{MATERIALS AND METHODS}

\section{Materials}

The tested thermoplastic prepregs were commercial pre-consolidated plates supplied by Solvay (Saint-Fons, France). They were made up of four stacked layers of twill 2-2 glass fiber (GF) fabrics impregnated with a PA66 thermoplastic matrix. Their initial volume fraction of fibers $\phi_{0}$ and thickness $h_{0}$ were 0.5 and $2 \pm 0.2 \mathrm{~mm}$, respectively.

\section{Bias-extension tests}

Bias-extension tests were conducted using a specially designed setup. Rectangular specimen with in-plane initial dimension of $270 \times 70 \mathrm{~mm}^{2}$ were placed in a furnace mounted on an electromechanical tensile testing machine (Zwick, load cell $50 \mathrm{kN}$ ). Specially designed clamps were used to ensure a constant and homogeneous clamping force to minimize the sliding of specimens. During the tests, the temperature of specimens was controlled using four thermocouples inserted along the sample gauge length into small holes drilled into the specimens.

The thermal history of samples during thermoforming is a crucial factor with a large influence on the deformation mechanisms. Thus, specimens were subjected to a thermal heating cycle that mimicked the industrial conditions (Fig. 1a). In this cycle, the material was heated above its melting temperature (A). This stage is representative of the pre-heating stage. Then, the temperature was decreased (cooling stage) down to the testing temperature (B). This stage is representative of the transport stage. During this period, the temperature decreased significantly from approximately $30-40^{\circ} \mathrm{C}$. The temperature was then homogenized in the entire specimen in order to reduce temperature gradients (C). Finally, the specimens were deformed (D). Experiments were performed at various testing temperatures $\left(270-290^{\circ} \mathrm{C}\right)$ and by imposing displacement increments of $10 \mathrm{~mm}$ (constant clamp relative displacement of $30 \mathrm{~mm} \cdot \mathrm{min}^{-1}$ ) for a total displacement of $50 \mathrm{~mm}$. Between each displacement step, the clamps remained fixed for $60 \mathrm{~s}$ to enable the specimen relaxation (Fig. 1b). 


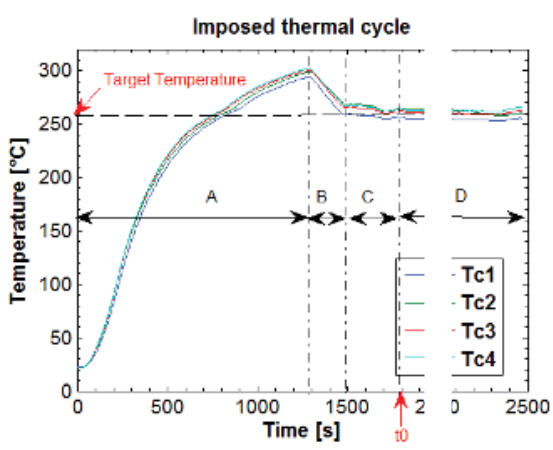

(a)

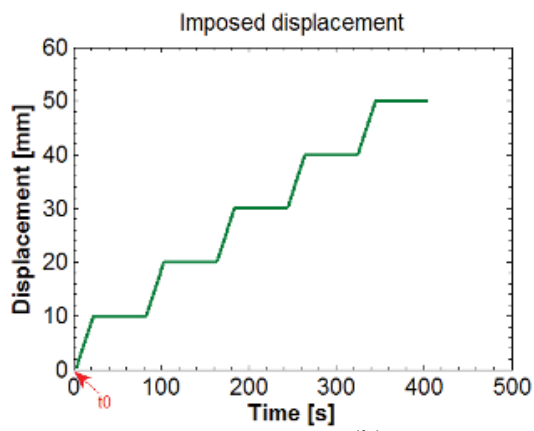

(b)

FIGURE 1: Bias-extension test, (a) Thermal cycle, (b) imposed clamp displacement to the specimen.

\section{$3 D$ imaging of the sample mesostructures}

Specimens were scanned using a laboratory X-ray microtomograph (3SR Lab, Grenoble, France, RX Solutions), with a voxel size of $47 \mu \mathrm{m}$ and a beam energy set to $100 \mathrm{kV}$ and $300 \mu \mathrm{A}$. Using $1984 \mathrm{X}$-ray projections and suitable reconstruction algorithm, 3D images were obtained. These images were used to obtain several mesostructure descriptors such as the local orientation angle of fibre bundles, fibre bundle volume fraction, and local thickness of samples.

All these structural descriptors were obtained from three samples tested at $270^{\circ} \mathrm{C}, 280^{\circ} \mathrm{C}$ and $290^{\circ} \mathrm{C}$, respectively. For each specimen, three representative Zones were scanned (Fig. 2). These 3D volumes were divided into small unit cells, i.e., representative elementary volumes (REV) with in-plane dimensions of $\approx 8 \times 8 \mathrm{~mm}^{2}$ (Fig. 2). In each of these cells, the orientation analysis was performed using the so-called structure tensor computed via the OrientationJ plugin implemented in ImageJ (9). This algorithm provided a local orientation for each voxel of the gray scale images (Fig. 4a-b). The orientation angle $\theta$ between the weft and warp directions was obtained by analyzing the orientation distribution function of the structure tensors in the deformed REVs. Assuming that in the initial state, the weft direction and the warp direction were perpendicular, i.e., $\theta_{0}=\pi / 2$, the local shear angle was computed as follows:

Using X-ray microtomography images, 2D maps of the volume fraction of fiber bundles and the sample thickness maps were also obtained. For that purpose, the $3 \mathrm{D}$ images were first binarized to separate voxels belonging to the fibrous phase from a phase containing the matrix and pores. This was achieved using the Otsu thresholding algorithm implemented in Image J. Then, for each voxel position in the plane of the samples, the thickness variation of the sample was estimated, as well as the mean relative volume fraction of bundle in the thickness

$\bar{\phi} \quad-\int \quad h$, as shown in Figs. 5a-c and 6a-c, respectively. Finally, these local values were averaged to obtain mean 2D value per REV, as shown in the graphs of Figs. $5 \mathrm{~d}$ and $6 \mathrm{~d}$.

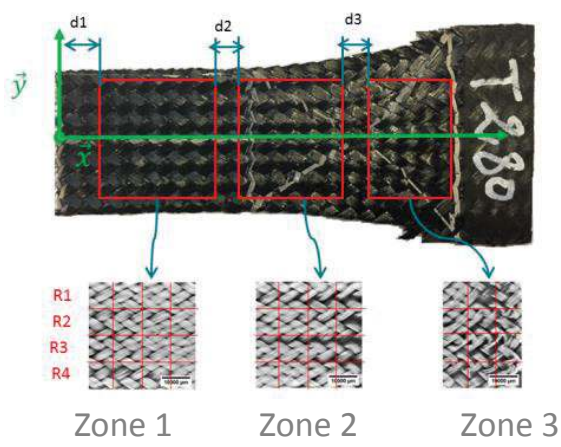

FIGURE 2: Top: positions of the scanned specimens delimited (red boxes). Box 1 is shown on the left-hand side of the top image, whereas box 3 is shown on the right-hand side. Bottom: discretization of 3D volumes into REV cells used for the microstructural analyzes. $\mathrm{Ri}(\mathrm{i}=1,2,3)$ are lines number. di $(\mathrm{i}=1,2,3)$ are distances between delimited boxes. 


\section{MECHANICAL PROPERTIES}

Fig. 3 shows the evolution of the loading force as a function of time for test temperatures of $270^{\circ} \mathrm{C}, 280^{\circ} \mathrm{C}$ and $290^{\circ} \mathrm{C}$. Whilst increasing the displacement, the loading force gradually increased. However, after each displacement interruption, the force also exhibited a pronounced relaxation, revealing the viscoelastic behavior of the thermoplastic prepreg (3). Furthermore, the loading force decreased as the testing temperature increased (3). The overall behavior of this thermoplastic prepregs was typical of woven fabrics. At low tensile elongation $L / L_{0}$, the macroscopic response is usually associated to free rotation of bundles: the shear resistance of the prepreg is low since only friction efforts between bundles occur. Then, the force gradually increases as fiber bundles progressively align along the tensile direction, come into lateral contacts and are subjected to transverse compression.

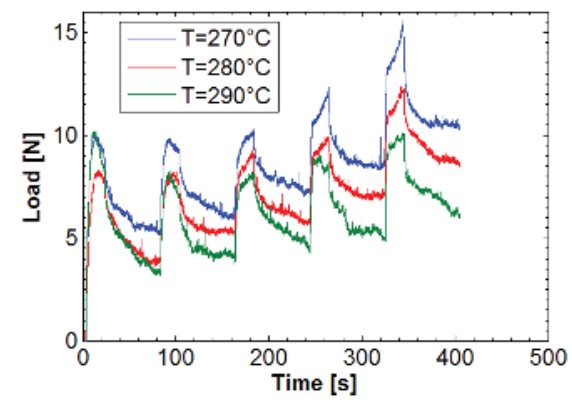

FIGURE 3: Bias-extension test: load vs. time at different temperatures.

\section{MICROSTRUCTURAL PROPERTIES}

\section{Shear angle}

Figs. $4 \mathrm{a}$ and $4 \mathrm{~b}$ show a typical in-plane slice REV before and after the image treatment used to determine the local orientation map for the prepreg fabric, respectively. These figures show that bundles exhibited two principal directions related to the warp and weft directions. Fig. 4c shows the evolution of the shear angle along the length of the specimen, both in the middle of the sample (R23, averaged values of the REVs of lines 2 and 3 ) and near its lateral faces (R14, averaged values of the REVs of lines 1 and 4). We first proved (not shown here) that the shear angle did not depend on the considered layer of the samples. In addition, it is noticeable that the shear angle decreased whilst approaching the clamp (right hand-side of Fig. 2c). Lastly, in the middle of the sample, the measured shear angle is much lower than that predicted from Eq. (1), as already pointed out in previous works (3).

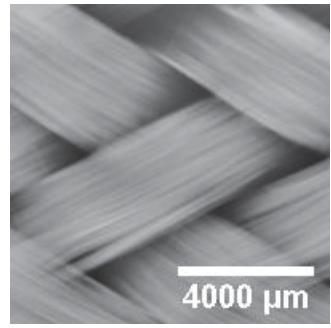

(a)

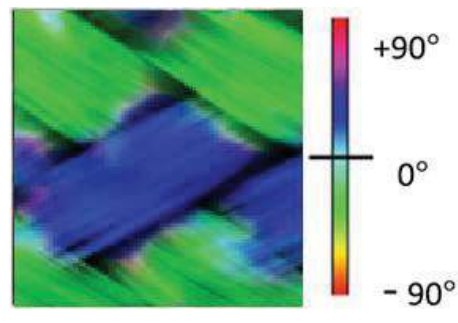

(b)

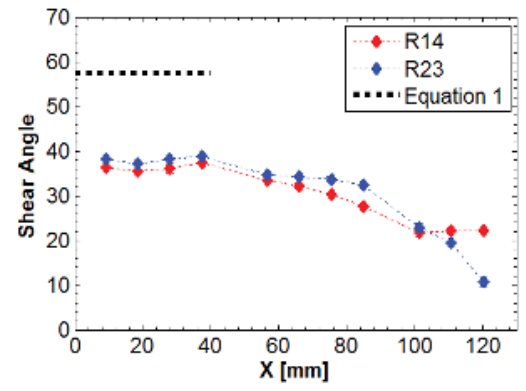

(c)

FIGURE 4: $280^{\circ} \mathrm{C}$-specimen. (a) Typical REV. (b) Orientation map. (c) Evolution of the local shear angle as a function of the horizontal position of the REV along the tested specimen.

\section{Fiber content and thickness maps}

Figs. 5a-c shows maps of $\bar{\phi}$ in each of the three aforementioned zones. These maps show large heterogeneities that were all the more important as the zone was located close to the clamps. This trend is confirmed by the evolution of the normalized fiber content $\bar{\phi}$ along the specimen length, as shown in Fig. 5d. The decrease in fiber content was 
associated to an increase in the porosity of the specimens. Both were induced by in-plane and out-of-plane bending and local buckling fiber bundles, as well as intra-bundle deconsolidation. These phenomena also conducted to a large increase in the local thickness of the specimens, as shown in the thickness maps and profiles shown in Fig. 6. Locally, the thickness increase ranged between $50 \%$ and $100 \%$ (Fig. 6d). Thus, the macroscale in-plane shear deformation induced the deconsolidation of the thermoplastic prepregs and resulted in large microstructural variations. Similar observations were done for all tested specimens.

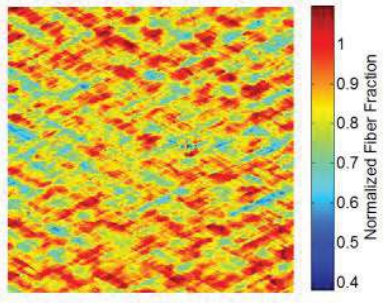

(a)-Zone 1

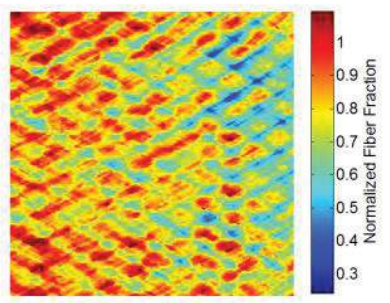

(b)-Zone 2

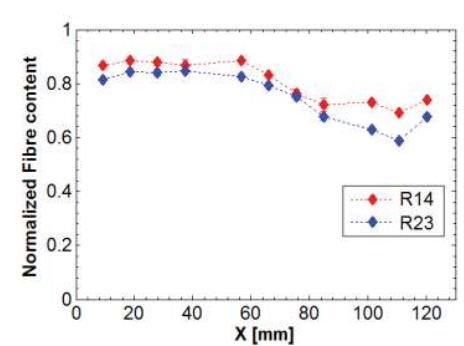

(d)

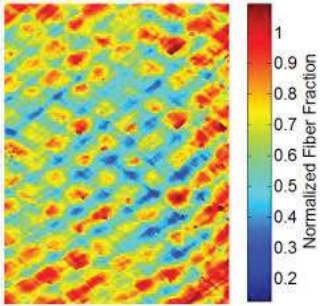

(c)-Zone 3

FIGURE 5 : $280^{\circ} \mathrm{C}$-specimen. Fiber content $\overline{\boldsymbol{\phi}}$ maps of Zone 1 (a), 2 (b) and 3 (c). (d) Fiber content $\overline{\boldsymbol{\phi}}$ variation along the horizontal direction (referring to Fig. 2 in raws 1-4 and 2-3).

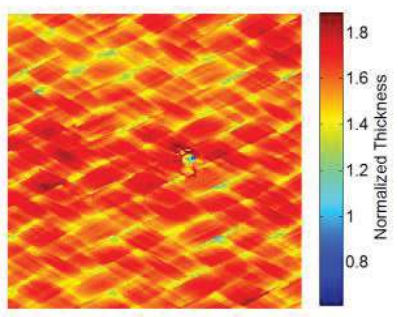

(a)-Zone 1

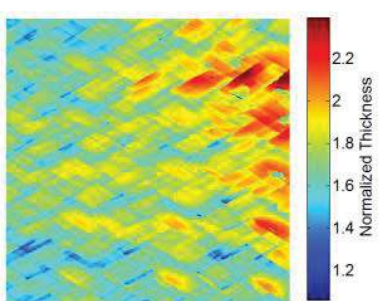

(b)-Zone 2

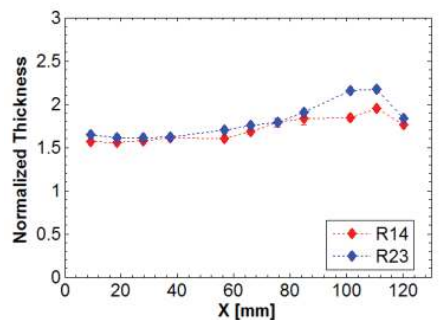

(d)

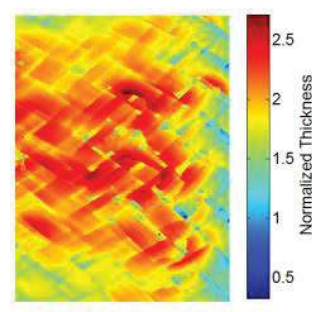

(c)-Zone 3

FIGURE 6: $280^{\circ} \mathrm{C}$-specimen. Normalized thickness maps of Zones 1 (a), 2 (b) and 3 (c). (d) Normalized thickness variation along the horizontal direction for raws 1-4 and 2-3 (referring to Fig. 2).

Fig. 7 shows that the profile evolutions for the shear angle, normalized fiber content, and normalized thickness were in general similar for all temperatures. However, some differences were noticed for the lowest testing temperature of $270^{\circ} \mathrm{C}$. The decrease in the shear angle was slightly enhanced for this temperature whilst approaching the clamp (Fig. 7a). Again, the normalized fiber content was slightly affected and exhibited a larger decrease. The most noticeable effect was obtained for the variation in the normalized thickness, which was clearly enhanced for the specimen deformed at $270^{\circ} \mathrm{C}$. The potential origins of these phenomena are complex and could be related for 
example to a variation in the in-plane and out-of-plane bending rigidity of fiber bundles accompanied with an increase in the local loading due to an increase in local inter-bundle interaction forces and moments.

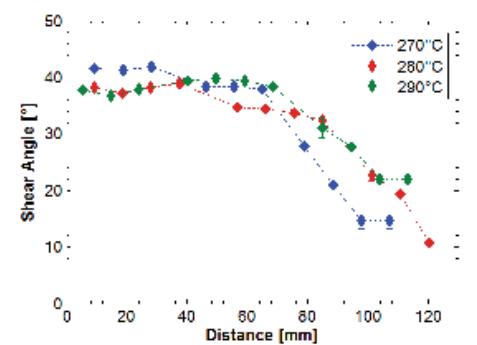

(a)

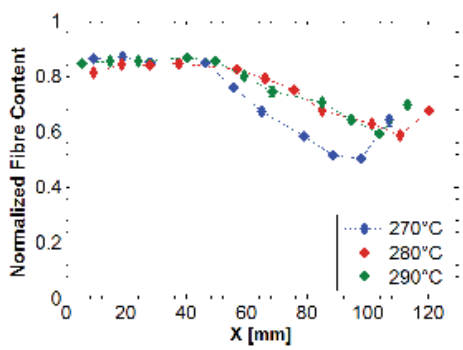

(b)

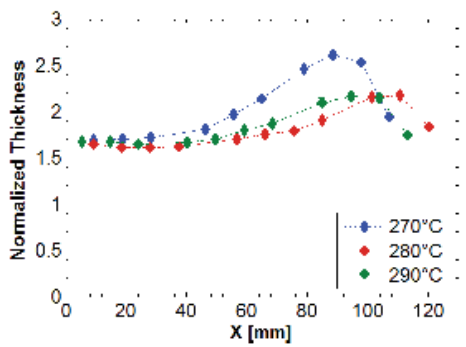

(c)

FIGURE 7: Evolution of the thermoplastic prepreg mesostructure for different temperatures: (a) shear angle, (b) normalized fiber content, (c) normalized thickness.

\section{CONCLUSION}

The objective of this study was to investigate the mesostructural changes of thermoplastic prepregs induced during bias-extension. These tests were performed on a pre-consolidated multilayer woven GF-PA66 prepregs using testing temperatures and thermal cycles that were representative of the thermoforming process. Results also showed that the in-plane-shear resistance increased for the lowest testing temperatures, corresponding to complex local deformation mechanisms as revealed by the analysis of the local evolution of several mesostructural characteristics such as fiber orientation, fiber volume fraction, local thickness and bundle shapes. These experiments also revealed the effect of the testing temperature on the evolution of these descriptors. All this information will form a unique database for the multiscale modelling of thermoforming of thermoplastic prepregs.

\section{ACKNOWLEDGEMENTS}

This study is part of the COMMANDO-STAMP project managed by IRT Jules Verne (French Institute in Research and Technology in Advanced Manufacturing Technologies for Composite, Metallic and Hybrid Structures). The authors wish to associate the industrial and academic partners of this project, respectively CEMCAT, PSA Group, SAFRAN, SOLVAY, and 3SR Lab, GeM, LaMCoS, LTN.

\section{REFERENCES}

1. K. Friedrich, M. Hou, J. Krebs, in Composite Sheet Forming, edited by D. Bhattacharyya, Elsevier Science B.V., Amsterdam, pp. 91-162 (1997).

2. S.G. Advani, T.S. Creasy, S.F. Shuler, in Composite Sheet Forming, edited by D. Bhattacharyya, Elsevier Science B.V., Amsterdam, pp. 323-368 (1997).

3. E. Guzman-Maldonado, N. Hamila, P. Boisse, J. Bikard, Composites Part A .78, 211-222 (2015).

4. P. Harrison, M.J. Clifford, A.C. Long, Composites Science and Technology 64, 1453-1465 (2004).

5. J. Cao, H.S. Cheng, T.X. Yu, B. Zhu, X.M. Tao, S.V. Lomov, Tz. Stoilova, I. Verpoest, P. Boisse, J. Launay, G. Hivet, L. Liu, J. Chen, E.F. de Graaf, R. Akkerman, Compos. Part A-Appl. S. 39, 1037-1053 (2008).

6. H. Alshahrani, R. Mohan, M. Hojjati, Int. J. Compos. Mater. 5(4), 81-87 (2015).

7. G. Lebrun, M.N. Bureau, J. Denault, Compos. Struct. 61(4):341-352 (2003).

8. M. Krause, J.M. Hausherr, B. Burgeth, C. Herrmann, W. Krenke, J. Mater. Sci. 45, 888-896 (2010).

9. J. Schindelin, I. Arganda-Carreras, E. Frise, V. Kaynig, M. Longair, T. Pietzsch, S. Preibisch, C. Rueden, S. Saalfeld, B. Schmid, J.-Y. Tinevez, D. White, V. Hartenstein, K. Eliceiri, P. Tomancak, A. Cardona, Nat. Methods 9, (2012). 